Arkivoc

Free to Authors and Readers
A Platinum Open Access Journal for Organic Chemistry

Paper

Arkivoc 2021, part x, 0-0 to be inserted by editorial office

\title{
Dichotomous stereocontrol in Claisen-Schmidt condensations: synthesis of a propeller shaped rigid system
}

\author{
C. Nithya, C. S. Aswathi, and T. S. Saumya *
}

Department of Applied Chemistry, Cochin University of Science \& Technology, Kochi-682022, Kerala, India Email: saumyatsoman@gmail.com

Received 03-26-2021

Accepted Manuscript 08-15-2021

Published on line $08-29-2021$

\section{Abstract}

Generally, Claisen-Schimdt condensation produces E-isomers of enones. However, in the Claisen Schimdt condensation between tetrahydropentalene-2,5(1H,3H)-dione and aromatic aldehydes, though initial condensations proceeded with the expected stereochemistry, subsequent condensations, where possible, produced the unexpected Z-isomers.
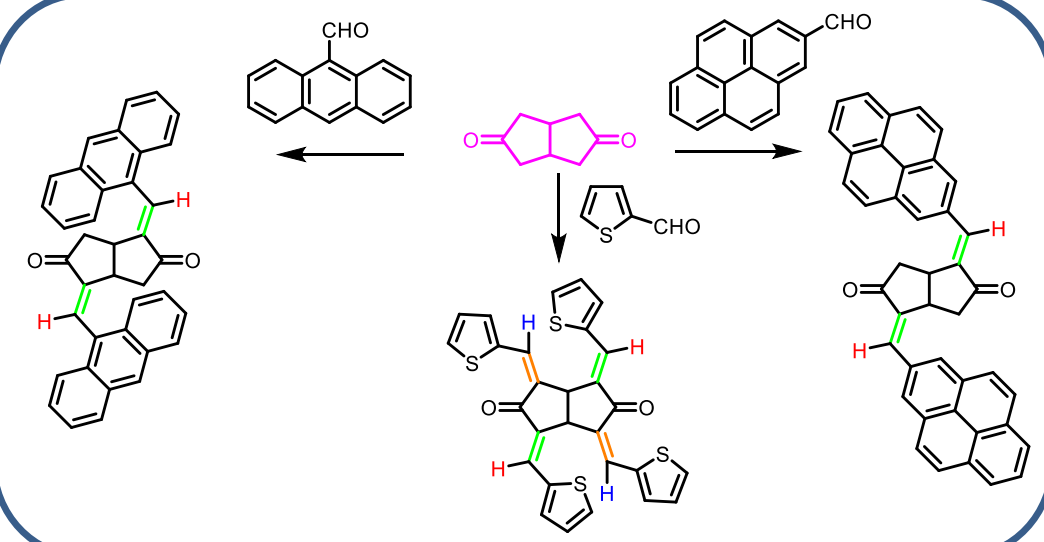

Keywords: Claisen-Schmidt condensation, regioselectivity, tetrahydropentalene-2,5(1H,3H)-dione, thiophene2-carboxaldehyde, anthraldehyde, pyrene-2-carboxaldehyde 


\section{Introduction}

Apart from being versatile photoactive molecules, bisarylidenecycloalkanones exhibit interesting biological activities including antitumor, ${ }^{1-3}$ antitubercular, ${ }^{4}$ and antioxidant properties. ${ }^{5,6}$ These compounds are conveniently prepared by Claisen-Schimdt condensation $^{7-10}$ between cycloalkanones and aromatic aldehydes. ${ }^{11}$ In the present study, we have examined the Claisen-Schmidt condensation between a cyclic diketone viz, tetrahydropentalene-2,5(1H,3H)-dione (1) and aldehydes $2 \mathrm{a}-\mathrm{c}$ with a view to synthesizing the corresponding tetraarylidine derivatives (Chart 1). ${ }^{12,13}$ We recognized this as a simple strategy to incorporate several aromatic residues in a highly ordered fashion into a compact structural unit. ${ }^{14}$ Incipient tetraarylidenediketones are expected to have interesting properties. Both tetrapyran-2-ylidine and tetraanthracen-9-ylidene derivatives should exhibit intense fluorescence while terathiophen-2-ylidine derivatives should act as ideal monomers for the generation of highly cross linked polymers. ${ }^{15-18}$ In principle, reaction between $\mathbf{1}$ and aromatic aldehydes $\mathbf{2}$ can give seven isomeric tetraarylidine derivatives A-G (Chart $\mathbf{1}$ ).

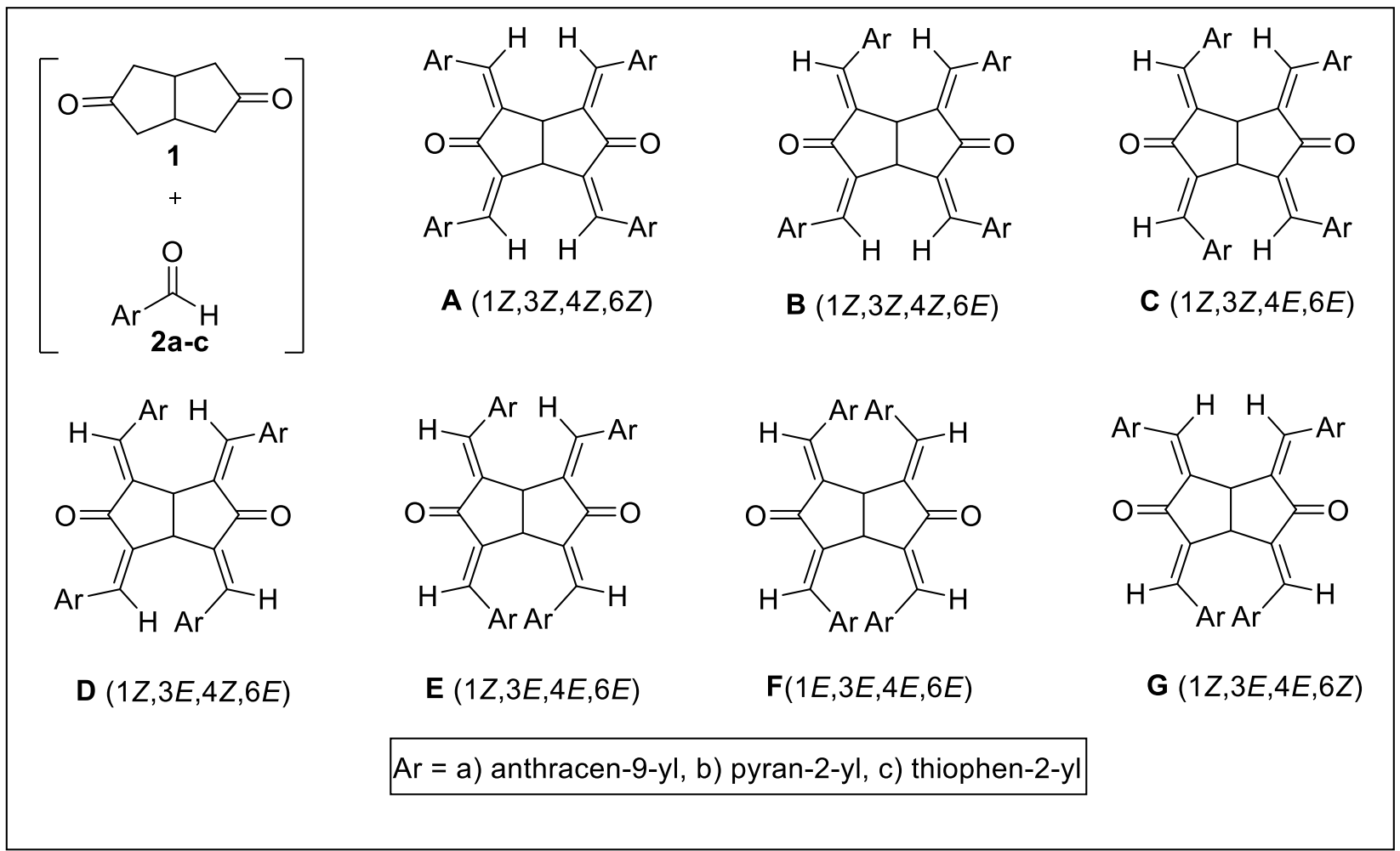

Chart 1

Among A-G, based on known stereochemical preference for Claisen Schimdt condensation, the E,E,E,Eisomer $\mathbf{F}$ is expected to be the most likely product. ${ }^{19}$ However, $\mathbf{F}$ suffers from steric crowding of aryl residues. Steric crowding is prominent in $\mathbf{E}$ and $\mathbf{G}$ as well. In order to avoid steric crowding, both $\mathbf{E}$ and $\mathbf{G}$ can assume nonplanar structures, but with concomitant loss in extended conjugation. All $Z$ isomer $\mathbf{A}$ and $Z, Z, Z, E$ isomer $\mathbf{B}$ are less likely products. This leaves $\mathbf{C}$ with $C_{2}$ symmetry and $\mathbf{D}$ possessing $\sigma_{2}$ symmetry as the most probable structures. Thus, the reaction between $\mathbf{1}$ and aryl aldehydes $\mathbf{2}$ provides an exciting platform to investigate regio and stereochemical preferences of the Claisen Schimidt condensation. We were hence interested in exploiting the synthetic potential and unraveling the mechanism of this reaction. In the present investigation, 
we examined the base catalyzed reaction between $\mathbf{1}$ and aromatic aldehydes such as anthracene-9carbaldehyde (2a), pyrene-2-carbaldehyde (2b) and thiophene-2-carbaldehyde (2c) (Chart 2).

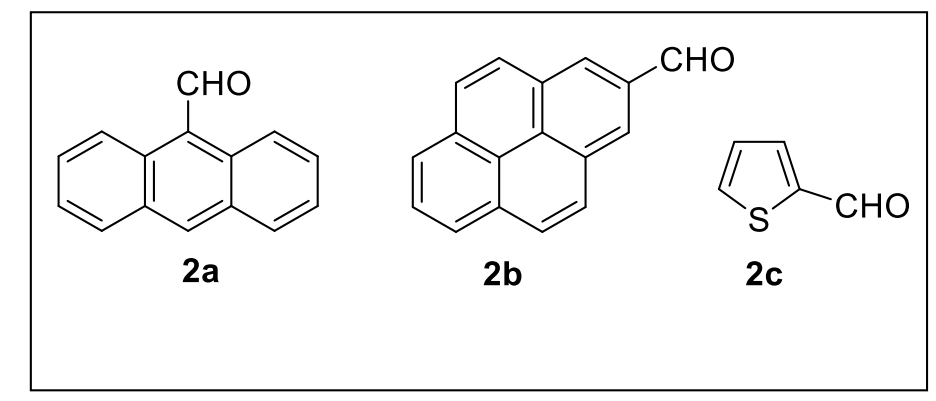

\section{Chart 2}

\section{Results and Discussion}

We synthesized tetrahydropentalene-2,5(1H,3H)-dione $(\mathbf{1})$ using Weiss-Cook procedure. ${ }^{20}$ This compound was subjected to Claisen-Schmidt condensation with anthracene-9-carboxaldehyde (2a), pyrene-2-carboxaldehyde (2b), and thiophene-2-carboxaldehyde (2c). Reaction between $\mathbf{1}$ and aldehydes $\mathbf{2 a}$ and $\mathbf{2 b}$ (4 eqv.) gave the corresponding 1,4-diarylidine derivatives $\mathbf{3}$ and $\mathbf{5}$ in good yields (Scheme 1). Structure of $\mathbf{3}$ and $\mathbf{5}$ were assigned on the basis of spectral and analytical data. Diketone $\mathbf{1}$ has four active methylene groups and hence four aldehyde molecules can, in principle condense with 1. MS data of $\mathbf{3}$ and $\mathbf{5}$ clearly indicated the formation of 1:2 condensation products. NMR spectra of $\mathbf{3}$ and $\mathbf{5}$ agreed with the condensation taking place at the 1 and 4 positions of 1 . Based on literature precedencies and appearance of the vinylic protons downfield around $\delta$ 8.50, E configuration was assigned to the double bonds in $\mathbf{3}$ and $\mathbf{5}$. $^{21,22}$ Treatment of $\mathbf{3}$ with excess of $\mathbf{2 a}$ (and $\mathbf{5}$ with excess $\mathbf{2 b}$ ) under harsher conditions failed to induce further condensation; slow decomposition of $\mathbf{3}$ and $\mathbf{5}$ was the only observed transformation. We attribute steric factors induced by bulky anthracene and pyrene components in $\mathbf{3}$ and $\mathbf{5}$ for restricting condensation to 1 and 3 positions. In order to extend condensation at the two remaining methylene carbons, both $\mathbf{3}$ and $\mathbf{5}$ were further subjected to reaction with relatively smaller molecules such as benzaldehyde, 4-nitrobenzaldehyde and thiophene-2-carbaldehyde (2c). Even after prolonged treatment under harsh conditions, both $\mathbf{3}$ and $\mathbf{5}$ resisted further condensations. These results are noteworthy since they provide information on three different aspects of the condensation reaction with bulky aldehydes: i) reaction takes place at distal 1,3-positions, ii) the stereochemical outcome is $E$, and iii) steric and/or electronic factors disfavor further condensations.

In continuation we examined the base catalyzed reaction between 1 and thiophene-2-carbaldehyde (2c) taken in a 1:4 ratio. Unlike in the condensation with bulky aldehydes such as $\mathbf{2 a}$ and $\mathbf{2} \mathbf{b}, \mathbf{1}$ underwent condensation with $\mathbf{2 c}$ at all the four methylene carbons to give a 1:4 condensation product as a single isomer (6) in $72 \%$ yield. Interestingly the 1:2 condensation product 4 could not be detected in the product mixture. In an attempt to arrest the reaction at 1:2 condensation stage, we repeated the reaction with $\mathbf{1}$ and $\mathbf{2 c}$ taken in a 1:2 ratio. Even under these conditions, (6) was the only product formed with "excess" 1 remaining unchanged. Thus, in contrast to $1: 2$ adducts $\mathbf{3}$ and $\mathbf{5}$ that resisted further condensation reactions, 1:2 adduct $\mathbf{4}$ appears to be even more reactive than 1 towards condensation (Scheme 1 ). 


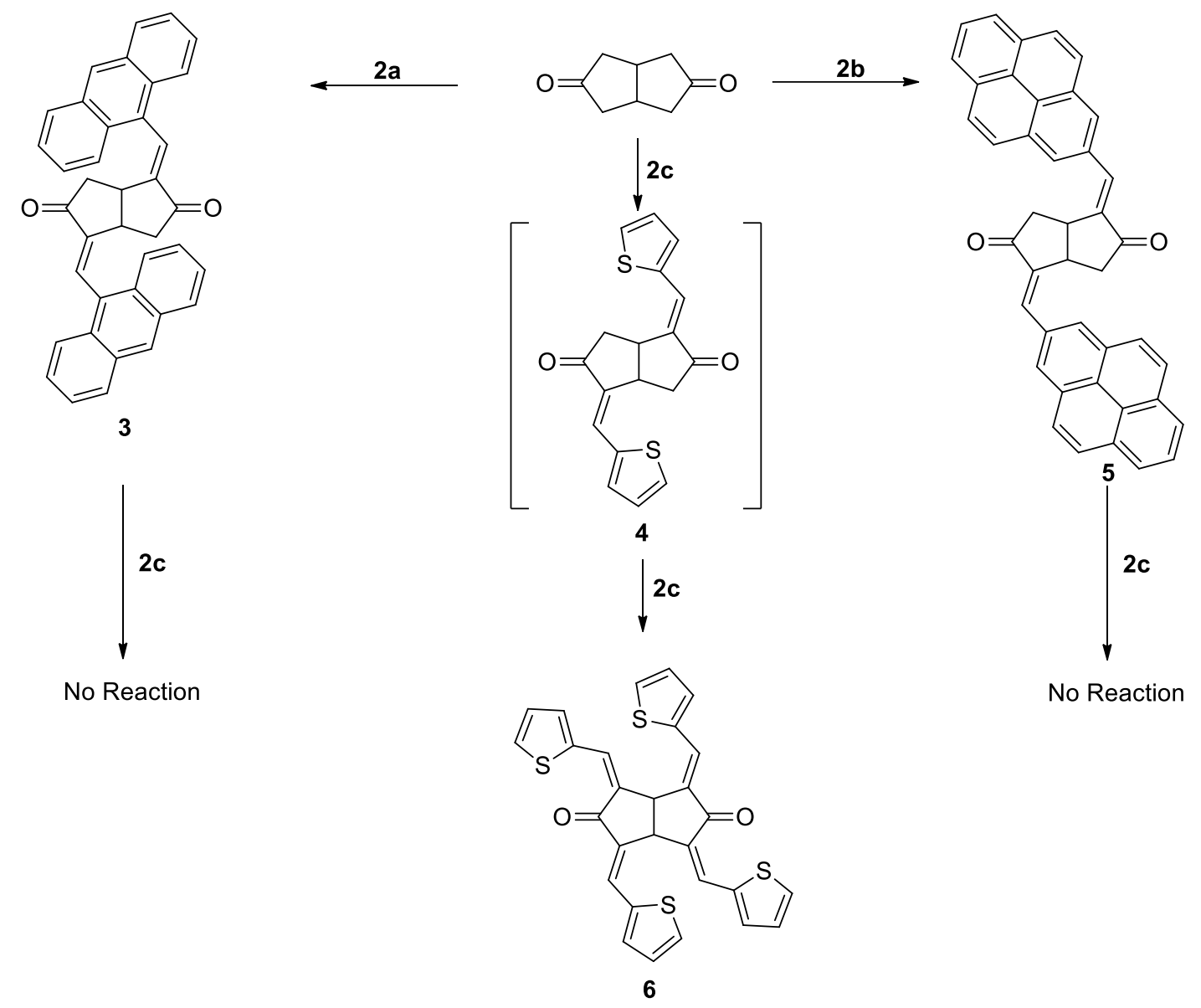

\section{Scheme 1}

Structure of 6 was identified on the basis of spectral and analytical data. MS data indicated its identity as a 1:4 condensation product. Assigning the stereochemistry of 6 was challenging, but could be accomplished on the basis of NMR spectral data. Among the seven possible isomers A-G (Chart 1 ), the all $Z$ and all $E$ isomers ( $A$ and $\mathbf{F}$ respectively), based on their higher order of symmetry, are expected to exhibit fewer signals in their NMR spectra. Isomers $\mathbf{B}$ and $\mathbf{E}$ on the other hand are expected to give maximum number of signals. Isomers C,D and $\mathbf{G}$ having two each of $E$ and $Z$ double bonds are expected to show the vinylic protons as two distinct singlets ( 2 protons each). However, in the case of isomer $\mathbf{G}$, the two methine protons are not chemical shift equivalent and hence are expected to appear as a pattern of two doublets. In isomer $\mathbf{C}$, the two methine protons are enantiotopic in nature and hence are chemical shift equivalent. On the other hand, the two methine protons in $\mathbf{D}$ are homotopic and are also chemical shift equivalent. Hence, though differentiating between $\mathbf{C}$ and $\mathbf{D}$ on the basis of simple ${ }^{1} \mathrm{H}$ NMR spectral data is difficult, they can easily be distinguished between each other on the basis of ${ }^{13} \mathrm{C} N M R$ spectral data. In isomer $\mathbf{D}$ possessing $\sigma_{2}$ symmetry, the two carbonyl carbons are chemical shift equivalent and hence should appear as a single peak. In the case of isomer C, the two carbonyl carbons are not chemical shift equivalent and hence should appear as two distinct signals. Since the vinylic protons appeared as two distinct signals and methine protons as a singlet in the ${ }^{1} \mathrm{H} N M R$ spectrum of 6 , and the two carbonyl carbon appeared a single peak in its ${ }^{13} \mathrm{C} N M R$ spectrum, we identified the structure of the 1:4 adduct as $(1 Z, 3 E, 4 Z, 6 E)$-1,3,4,6-tetrakis(thiophen-2-ylmethylene)tetrahydropentalene2,5(1H,3H)-dione (6) (Figure 1). 


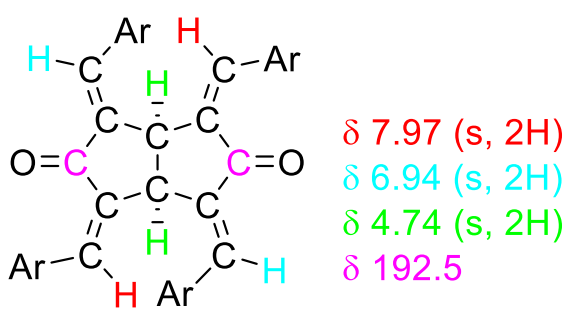

Figure 1

The mechanism for the formation of 6 may be understood in terms of the pathways shown in Scheme 1. Initial condensations may be occurring at the 1 and 3 positions of 1 to give the $E, E$-isomer 4 . This assumption is based on the results obtained in the reaction between $\mathbf{1}$ and $\mathbf{2 a} \mathbf{a} \mathbf{b}$. Further condensations at 3 and 6 positions followed by stereoselective dehydration yields two new double bonds having the Z-geometry. The volte-face in stereocontrol is understood in terms of opposing demands of electronic and steric factors that settles for the $Z, E, Z, E$-isomer as the best compromise.

\section{Conclusions}

We have exploited sequential Claisen-Schmidt condensation for the synthesis of a rigid propeller shaped molecule and demonstrated a rare example for both $E$ and $Z$ selectivity in a domino sequence of the same reaction carried out under identical conditions. Our results indicate that steric factors are important in controlling stereoselectivity in Claisen-Schmidt condensations.

\section{Experimental Section}

General. All reactions were carried out using oven dried glasswares. All experiments were done with distilled and dried solvents by using standard protocols. All starting materials were purchased from either SigmaAldrich or Spectrochem Chemicals and were used without further purification. Separation and purification of compounds were done by recrystallization technique. Melting points are uncorrected and were determined on a Neolab melting point apparatus. Infra-red spectra were recorded using Jasco 4100 and ABB Bomem (MB Series) FT-IR spectrometers. The ${ }^{1} \mathrm{H}$ and ${ }^{13} \mathrm{C}$ NMR spectra were recorded at $400 \mathrm{MHz}$ Bruker Avance III FT-NMR spectrometer with tetramethylsilane (TMS) as internal standard. Chemical shifts ( $\delta$ ) are reported in parts per million (ppm) downfield of TMS. Here we are giving the spectral and analytical data only for novel compounds and the corresponding reference cited for known compounds.

Tetrahydropentalene-2,5(1H,3H)-dione (1) was prepared using the Weiss-Cook procedure. ${ }^{19}$ $(1 Z, 3 E, 4 Z, 6 E)-1,3,4-T r i s(t h i o p h e n-2-y l m e t h y l e n e)-6-(t h i o p h e n-3-y l$ methylene) tetrahydro- pentalene$\mathbf{2 , 5}(\mathbf{1 H}, \mathbf{3 H})$-dione (6). To a mixture of compound $\mathbf{1}(0.14 \mathrm{~g}, 1 \mathrm{mmol})$ and thiophene-2-carboxaldehyde $(\mathbf{2 c}, 0.45$ $\mathrm{g}, 4 \mathrm{mmol})$ in methanol $(25 \mathrm{~mL})$ taken in $100 \mathrm{~mL}$ flask, potassium hydroxide pellets $(0.22 \mathrm{~g}, 4 \mathrm{mmol})$ were added and the reaction mixture was stirred at room temperature overnight whilst a greenish brown precipitate separated out.The crude product $(1 Z, 3 E, 4 Z, 6 E)-1,3,4$-tris(thiophen-2-ylmethylene)-6-(thiophen-3- 
ylmethylene)tetrahydropentalene-2,5(1H,3H)-dione was washed several times with $1 \mathrm{~mL}$ portions of ice cold ethanol.

(1Z,3E,4Z,6E)-1,3,4-Tris(thiophen-2-ylmethylene)-6-(thiophen-3-yl methylene) tetrahydro- pentalene2,5(1H,3H)-dione (6). Yield 72\%; $\mathrm{mp} 208{ }^{\circ} \mathrm{C}(\mathrm{dc})$; IR (KBr) 3056, 3009, 2948, 2841, 1656, 1600, 1576, 1511, $1263 \mathrm{~cm}^{-1} ;{ }^{1} \mathrm{H}$ NMR $\left(400 \mathrm{MHz}, \mathrm{CDCl}_{3}\right): \delta 7.97(\mathrm{~s}, 2 \mathrm{H}), 7.52-7.31(\mathrm{~m}, 4 \mathrm{H}), 7.48-7.46(\mathrm{~d}, 2 \mathrm{H}), 7.32-7.31(\mathrm{~d}, 2 \mathrm{H})$, $6.94(\mathrm{~s}, 2 \mathrm{H}), 7.18-7.16\left(\mathrm{dd}, 2 \mathrm{H}, J_{1} 5.2 \mathrm{~Hz}\right.$ and $J_{2} 4 \mathrm{~Hz}$ ), 7.00-6.97 (dd, $2 \mathrm{H}, J_{1} 5.2 \mathrm{~Hz}$ and $\left.J_{2} 4 \mathrm{~Hz}\right), 4.74(\mathrm{~s}, 2 \mathrm{H}) .{ }^{13} \mathrm{C}$ NMR $\left(400 \mathrm{MHz}, \mathrm{CDCl}_{3}\right): 192.5,138.7,137.9,137.4,136.9,133.5,133.4,132.5,130.4,130.2,128.3,127.6$, 126.9, 46.7. MS: $m / z 514\left(M^{+}\right)$. Anal. Calcd. for $\mathrm{C}_{28} \mathrm{H}_{18} \mathrm{O}_{2} \mathrm{~S}_{4}: \mathrm{C}: 65.24, \mathrm{H}: 3.41$, S: 24.76. Found: C: $65.27, \mathrm{H}: 3.46$, S: 24.86.

(1E,4E)-1,4-Bis(anthracen-9-ylmethylene)tetrahydropentalene-2,5(1H,3H)-dione (3). To a mixture of compound 1 (0.14 g, $1 \mathrm{mmol})$ and anthraldehyde $(2 \mathrm{a}, 0.82 \mathrm{~g}, 4 \mathrm{mmol})$ in methanol $(25 \mathrm{~mL})$ taken in $100 \mathrm{~mL}$ flask, potassium hydroxide pellets $(0.22 \mathrm{~g}, 4 \mathrm{mmol})$ were added and the reaction mixture was stirred at room temperature overnight whilst an orange-red precipitate separated out. The crude product was washed several times with ice cold $1 \mathrm{~mL}$ portions of ethanol.

(1E,4E)-1,4-Bis(anthracen-9-ylmethylene)tetrahydropentalene-2,5(1H,3H)-dione (3). Yield: $62 \%, \mathrm{mp} 160{ }^{\circ} \mathrm{C}$ (dec); IR (KBr): 3047, 2853, 1632, 1406, 1276, $886 \mathrm{~cm}^{-1},{ }^{1} \mathrm{H}$ NMR (400 MHz, CDCl 3$): \delta 8.69(\mathrm{~s}, 1 \mathrm{H}), 8.49(\mathrm{~s}, 1 \mathrm{H})$, 8.05-8.03 (m, 4H), 7.57-7.49 (m, 4H), 3.50-3.46 (m, 1H), 1.46-1.44 (m, 2H) ; ${ }^{13} \mathrm{C} \mathrm{NMR}\left(400 \mathrm{MHz}^{\mathrm{C}} \mathrm{CDCl}_{3}\right): 196.1$, 146.1, 135.1, 131.2, 129.1, 128.8, 128.4, 126.6, 125.5, 125.3, 41.6, 38.5. MS: $m / z 514\left(M^{+}\right)$. Anal. Calcd. for $\mathrm{C}_{38} \mathrm{H}_{26} \mathrm{O}_{2}: \mathrm{C}: 88.60 ., \mathrm{H}: 5.03$. Found C: 88.69, $\mathrm{H}: 5.09$.

(1E,4E)-1,4-Bis(pyren-2-ylmethylene)tetrahydropentalene-2,5(1H,3H)-dione (5). To a mixture of compound 1 $(0.14 \mathrm{~g}, 1 \mathrm{mmol})$ and pyrene-2-carboxaldehyde $(\mathbf{2 b}, 0.92 \mathrm{~g}, 4 \mathrm{mmol})$ in methanol $(25 \mathrm{~mL})$ taken in $100 \mathrm{~mL}$ flask, potassium hydroxide pellets $(0.22 \mathrm{~g}, 4 \mathrm{mmol})$ were added and the reaction mixture was stirred at room temperature overnight whilst red precipitate separated out. The crude product was washed several times with ice cold $1 \mathrm{~mL}$ portions of ethanol.

(1E,4E)-1,4-Bis(pyren-2-ylmethylene)tetrahydropentalene-2,5(1H,3H)-dione (5) Yield: $50 \% ; \mathrm{mp} 180{ }^{0} \mathrm{C} ; \mathrm{IR}$ $(\mathrm{KBr}): 3042,1658,1592,645 \mathrm{~cm}^{-1} ;{ }^{1} \mathrm{H}$ NMR $\left(400 \mathrm{MHz}, \mathrm{CDCl}_{3}\right): \delta 8.75(\mathrm{~s}, 2 \mathrm{H}), 8.41-8.39(\mathrm{~m}, 2 \mathrm{H}), 8.21-8.16(\mathrm{~m}$, $2 \mathrm{H}), 8.13-8.10(\mathrm{~m}, 3 \mathrm{H}), 8.09-8.07(\mathrm{~m}, 4 \mathrm{H}), 8.03-8.01(\mathrm{~m}, 4 \mathrm{H}), 8.00-7.98(\mathrm{~m}, 4 \mathrm{H}), 4.18-4.15(\mathrm{~m}, 2 \mathrm{H}), 2.69-2.61$ $(\mathrm{m}, 2 \mathrm{H}), 2.21-2.15(\mathrm{~m}, 2 \mathrm{H})$; MS: $m / z 562\left(M^{+}\right)$. Anal. Calcd. for $\mathrm{C}_{42} \mathrm{H}_{26} \mathrm{O}_{2}$ : C: 89.60, $\mathrm{H}:$ 5.49. Found C: 89.66, $\mathrm{H}$ : 5.66 .

\section{Acknowledgements}

We thank STIC, Kochi for NMR and elemental analysis and FIST and PURSE grants from DST India for financial support. NC, STS and ACS gratefully acknowledge INSPIRE, CSIR and UGC respectively for financial support in the form of Research Fellowship, and Professor Unnikrishnan P. A. and Professor Prathapan S. for helpful discussions.

\section{Supplementary Material}

Supplementary material containing the ${ }^{1} \mathrm{H}$ and ${ }^{13} \mathrm{C}$ NMR spectra and other relevant information is available. 


\section{References}

1. Robinson, T. P.; Hubbard, R. B.; Ehlers, T. J.; Arbiser, J. L.; Goldsmith, D. J.; Bowen, J. P. Bioorg. Med. Chem. 2005, 13, 4007-4013.

https://doi.org/10.1016/j.bmc.2005.03.054

2. Bayomi, S. M.; Hassan, M.; Kashef, A. E.; Ashmawy, M. B.; Nasr, M. N. A.; Sherbeny, M. A.; Radria, F. A. Med. Chem. Res. 2012, 1147.

https://doi.org/10.1007/s00044-012-0116-9

3. Fatmah, A. O.; Hassan, A. M.; Ghahda, H.; Messery, E.; Shahenda, M.; Hussein, E. L. Eur. J. Med. Chem. 2012, $47,65$.

4. Hazarkhani, H.; Kumar, P.; Kondiram, K. S.; Shafi Gadwal, I. M. Synth. Commun. 2010, 40, 2887 https://doi.org/10.1080/00397910903340637

5. Dinkova-Kostova, A. T.; Abeygunawardana, C.; Talalay, P. J. Med. Chem. 1998, 41, 5287-5296. https://doi.org/10.1021/jm980424s

6. Rahman, A.; Ahmed, M.; Ali, H. M. Des. Monomers polym. 2013, 16(4), 377. https://doi.org/10.1080/15685551.2012.747155

7. Claisen, L.; Claparede, A. Ber. 1881, 14, 2460. https://doi.org/10.1002/cber.188101402192

8. Schmidt, J. G. Ber. 1881, 14, 1459. https://doi.org/10.1002/cber.188101401306

9. Vashchenko,V.; Kutulya, L.; Krivoshey, A. Synthesis 2007, 14, 2125. https://doi.org/10.1055/s-2007-983746

10. Yadav, G. D.; Wagh, D. P. Chemistryselect. 2020, 5, 9059-9085. https://doi.org/10.1002/slct.202001737

11. Esmaeili, A. A.; Tabas, M. S.; Naseri, M. A.; Kazemi, F. Monatsh. Chem. 2005, 136, 571-576. https://doi.org/10.1007/s00706-004-0256-9

12. Wayne, W.; Adkins, H. J. Am. Chem. Soc. 1940, 62, 3401. https://doi.org/10.1021/ja01869a033

13. Marvel, C. C.; King, W. B. Org. Synthesis 1944, 1, 252.

14. Nithya, C.; Sithambaresan, M.; Kurup, M. R. P. Acta Cryst. 2014, 72, 199.

15. Kolodziejczyk, B.; Mayevsky, D.; Winther-Jensen, B. RSC Adv. 2013, 3, 4568. https://doi.org/10.1039/c3ra23120h

16. Alkskas, A. I.; Alhubge, A. M.; Azam, F. Chin. J. Polym. Sci. 2013, 31, 471. https://doi.org/10.1007/s10118-013-1237-4

17. Liang, G.; Yang, S. L.; Wang, X.H.; Li, Y.R.; Li, X.K. Acta Cryst. 2007, 63, 4118. https://doi.org/10.1107/S160053680704531X

18. Gangadhara, K. K. Polymer 1995, 36, 1903-1910. https://doi.org/10.1016/0032-3861(95)90938-X

19. Al-Omran, F.; Mohareb, R. M.; El-Khair, A. A. Molecules 2011, 16, 6129.

20. Bertz, S. H.; Cook, J. M.; Gawish, A.; Weiss, U. Org. Synth. 1990, 7, 50.

21. Shaw, R.; Roane, D.; Nedd, S. J. Chem. Educ. 2002, 79 (1), 67. https://doi.org/10.1021/ed079p67

22. Abraham, R. J.; Canton, M.; Griffiths, L. Magn. Reson. Chem. 2001, 39, 421-431. https://doi.org/10.1002/mrc.862 
This paper is an open access article distributed under the terms of the Creative Commons Attribution (CC BY) license (http://creativecommons.org/licenses/by/4.0/) 